\title{
Femoral Osteomyelitis Due to Cladophialophora arxii in a patient with Chronic
} Granulomatous Disease

Tomonari Shigemura ${ }^{1}$, Kazunaga Agematsu ${ }^{1}$, Takashi Yamazaki ${ }^{1}$, Kasuga Eriko ${ }^{2}$, Gaku Yasuda $^{3}$, Kazuko Nishimura ${ }^{4}$ and Kenichi Koike ${ }^{1}$

Departments of ${ }^{1}$ Pediatrics and ${ }^{2}$ Laboratory Medicine and ${ }^{3}$ Orthopaedic Surgery, Shinshu University School of Medicine, Matsumoto, Nagano, Japan, and ${ }^{4}$ First Laboratories, Co., Ltd. and Medical Mycology Research Center, Chiba University, Chiba, Japan.

Running Title: Cladophialophora arxii infection in CGD

Key words: Chronic granulomatous disease, Osteomyelitis, Cladophialophora arxii, Itraconazole, interferon- $\gamma$.

Correspondence to Tomonari Shigemura, M.D., Department of Pediatrics, Shinshu University School of Medicine, 3-1-1, Asahi, Matsumoto 390-8621, Japan

Phone: +81-263-37-2642

Fax: +81-263-37-3089

E-mail: tomonari@shinshu-u.ac.jp 


\begin{abstract}
Fungal infections in patients with chronic granulomatous disease (CGD) are a poor prognostic factor. We describe the first case of CGD with femoral osteomyelitis due to Cladophialophora arxii, which is a member of dematiaceous group. The causative fungus was identified on the basis of its morphological characteristics, growth temperature profile and nucleotide sequence on the ITS region of the ribosomal gene. The patient was successfully treated with surgical debridement, subsequent administration of itraconazole and interferon- $\gamma$.
\end{abstract}




\section{Introduction}

Chronic granulomatous disease (CGD) is a rare inherited primary immunodeficiency of phagocytic cells due to low activity of nicotinamide adenine dinucleotide phosphate (NADPH) oxidase [1]. CGD patients are susceptible to infections, especially with catalase-producing bacteria, Staphylococcus, Burkholderia, Serratia, Nocardia, and fungi, such as Aspergillus species [2]. Cladophialophora arxii is one of the dematiaceous fungi. Dematiaceous fungi, characterized by black melanin pigment, are isolated less frequently in CGD patients.

We report a patient with CGD who developed femoral osteomyelitis due to C. arxii. The patient had successful treatment with surgical debridement and administration of itraconazole and interferon- $\gamma$.

\section{Case Report}

The patient was 20-year-old man with X-linked CGD. The diagnosis of CGD had been established at the age of 6 years; the patient had presented with cervical lymphadenitis, BCG lymphadenitis, a perirectal abscess, and recurrent pneumonia, and neutrophil nitroblue tetrazolium reduction was abnormal. He was treated with prophylactic therapy consisting of trimethoprim-sulfamethoxazole and oral itraconazole capsules (100 mg once daily), and developed no other serious infections until 20 years of age. However, pulmonary granulomas, which had been formed after an episode of pneumonia at the age of 7 years, remained and had been gradually growing over the past 13 years. He occasionally had hemoptysis.

The patient presented with an approximately 2-week history of pain in the posterior, distal left thigh without fever. On admission, he complained of knee pain that made walking difficult. Laboratory findings included: leukocyte count, 3,950/ $\mu 1$, with $76 \%$ neutrophils; 
C-reactive protein (CRP), $13.8 \mathrm{mg} / \mathrm{l}$; erythrocyte sedimentation rate, $23 \mathrm{~mm} / \mathrm{h}$; and B-D-glucan (ß- glucan Wako), $14.78 \mathrm{pg} / \mathrm{ml}$ (normal range $<11 \mathrm{pg} / \mathrm{ml}$ ). Before this episode, $\beta$-D-glucan levels had been negative. Aspergillus DNA and Aspergillus galactomannan antigen in blood were undetectable. Blood cultures showed no growth.

A roentgenogram of the painful area showed no abnormalities, but magnetic resonance imaging suggested osteomyelitis (Fig.1). A computerized tomography scan of the chest revealed a $2.5 \mathrm{~cm}$ nodule in the right hilar region, which partly compressed the bronchial tube, a $1.5 \mathrm{~cm}$ nodule in the left upper lobe, with numerous small nodules scattered throughout both lungs. Enlarged lymph nodes with calcification in the superior mediastinum, left axilla, and hepatic portal region were present. Empiric therapy with oral itraconazole solution (200 mg once daily) and intravenous injection of micafungin (250 $\mathrm{mg}$ per day) was started because the clinical and laboratory findings suggested fungal osteomyelitis. The plasma itraconazole concentration measured with use of high performance liquid chromatography, which was $626.0 \mathrm{ng} / \mathrm{ml}$ on admission, was elevated to $2,573.4 \mathrm{ng} / \mathrm{ml}$ on the third day of hospitalization. The following day, extensive surgical debridement of the lesion was performed. Discharge of pus was observed coming from the bone marrow after drilling of a hole in the cortex. Fungal elements were seen in the necrotic bone tissue. Culturing of this specimen on Sabouraud dextrose agar (Becton Dickinson Microbiology Systems, Tokyo, Japan) yielded several colonies with no bacteria present after 14 days. These colonies were dark gray and consisted of septate hyphae with smooth oval conidia. At this point, the fungus was tentatively identified as Cladosporium species. The patient showed clinical and laboratory signs of improvement on the $14^{\text {th }}$ day of hospitalization. Therapy with itraconazole and micafungin was continued, but the inflammatory markers rose gradually (CRP : from 2.7 to $10.5 \mathrm{mg} / \mathrm{l})$, and the plasma 
itraconazole concentration decreased to $1596.6 \mathrm{ng} / \mathrm{ml}$. Interferon (IFN)- $\gamma$ therapy $\left(25 \mu \mathrm{g} / \mathrm{m}^{2}\right.$ two times per week) was added to the therapeutic regimen on the $24^{\text {th }}$ day, and the route of itraconazole administration was changed on the $25^{\text {th }}$ day; the patient was treated with itraconazole intravenously for 12 days (200 mg once daily) followed by oral capsules (200 mg twice daily). These changes in the patient's therapeutic regimen increased the plasma itraconazole concentration to over 5,000 ng/ml, and the CRP level decreased to within the normal range. Micafungin was discontinued on the day of discharge $\left(40^{\text {th }}\right.$ day after admission), while treatment with itraconazole and IFN- $\gamma$ was continued. Plasma itraconazole levels stayed within the range of 7,000 to $8,000 \mathrm{ng} / \mathrm{ml}$. Five months after surgery, the patient had no signs of recurrent disease, but there was little change in pulmonary granulomas. There were no side effects as a result of the drugs given.

At the time of discharge, the isolated fungus was identified as Cladophialophora arxii. The MICs of itraconazole, micafungin, amphotericin B, voriconazole, flucytosine, miconazole, and fluconazole against the present isolate were $0.03 \mathrm{mg} / 1,0.125 \mathrm{mg} / \mathrm{l}, 0.25 \mathrm{mg} / \mathrm{l}, 0.5 \mathrm{mg} / \mathrm{l}, 1$ $\mathrm{mg} / \mathrm{l}, 1 \mathrm{mg} / \mathrm{l}$, and $64 \mathrm{mg} / \mathrm{l}$, respectively. The MICs were established after five days of incubation and determined by the ASTY (Kyokuto Pharmaceutical Industrial Co., Ltd., Tokyo) colorimetric microdilution testing [3]. Neutrophil superoxide production on flow cytometric analysis with dihydrorhodamine 123 was $0.3 \%$ of control neutrophils before IFN- $\gamma$ therapy. Despite continuous IFN- $\gamma$ therapy, no increase in superoxide production by the patient's neutrophils was observed on several occasions.

\section{Mycological Examination}

Colonies of the causative fungus grew slowly, attaining ca. $40 \mathrm{~mm}$ and ca. $36 \mathrm{~mm}$ in diameter on SDA (Difco) and potato dextrose agar (Difco) plates at $25^{\circ} \mathrm{C}$ after 35 days, respectively. 
They were dark grayish with aerial hyphae and blackish brown with creeping hyphae at the margin on SDA (Fig. 2 A) and blackish brown, felty with radial furrows on PDA. Hyphae were septate, olivaceous brown and produced laterally and terminally acropetal conidial chains that branched profusely. Conidia were pale brown to brown, smooth- and somewhat thick-walled, lemon- to spindle-shaped, 5-13 x 3-4 $\mu \mathrm{m}$ with hila (Fig.2 B). The isolate grew at $35{ }^{\circ} \mathrm{C}$ but restricted, barely at $37{ }^{\circ} \mathrm{C}$ and did not grow at $40{ }^{\circ} \mathrm{C}$.

DNA was extracted by the benzyl chloride method from isolates cultured on PDA at $25^{\circ} \mathrm{C}$ for 7 days and the internal transcribed spacer region including $5.8 \mathrm{~S}$ of ribosomal RNA gene (ITS1-5.8S-ITS2 rRNA) was amplified with the primer pair ITS5 (5'-GGA AGT AAA AGT CGT AAC AAG G-3') and ITS4 (5'-TCCTCCGCTTATTGATATG-3'). The PCR products were labeled by ITS1 (5'-TCC GTA GGT GAA CCT GCG G-3') and ITS4. A total of 528 bases determined showed a $98 \%$ homology against the ITS region in Cladophialophora arxii IFM 52022 (Accession No.AB109181), derived from the type strain CBS 306.94.

Based on these results, the causative fungus was identified as $C$. arxii and the sequence was registered at DNA Data Bank of Japan (DDBJ), National Institute of Genetics as Accession No. AB458597.

\section{Discussion}

CGD patients have frequent life-threatening bacterial and fungal infections because superoxide production is decreased in their phagocytes [1]. Such patients usually suffer from infections in the skin, lymph nodes, lungs, liver, and gastrointestinal tract. The lungs are the most common sites of infections. The overall incidence of fungal infections has been reported to be $20 \%$ among patients with CGD [4]. Aspergillus species are the most common cause of 
fungal infections, but there have been very few reports of other fungal infections. Although pulmonary infections due to Aspergillus species are common, fungal osteomyelitis due to Aspergillus species is uncommon. In particular, long bone osteomyelitis due to non-Aspergillus fungi has been rarely reported [5]. Osteomyelitis may be a part of systemic infection, or may be the only localized focus of infection. In the present case, he had pulmonary granulomas, which partly compressed the bronchial tube, and occasionally had hemoptysis. We hypothesized that the causative fungus disseminated into the bone lesion through the bloodstream from the lung lesion, which may have been caused by air-bone infection. Therefore, we expected that itraconazole therapy would at least diminish the size of the pulmonary granulomas which had formed over the past 13 years. However, it did not result in such a favorable response.

Cladophialophora arxii is a member of the dematiaceous group of mycelial fungal pathogens. This fungus was reported as a new species of the genus Cladophialophora in 1995 [6]. The species identification is difficult because of its rarity and morphological similarity among some Cladophialophora species. The conidial system morphology of the present fungus is very similar to that of Cladophialophora devriesii. In addition, $C$. devriesii grows at $37^{\circ} \mathrm{C}$ and not at $40^{\circ} \mathrm{C}$. However, conidial chains are slightly longer in the present fungus and the identity of the ITS region of the rRNA gene shows $89-90 \%$ similarity with $C$. devriesii. Even though the growth temperature profile is like that of $C$. devriesii, the conidial morphology and DNA identity strongly suggest that the present isolate is $C$. arxii but not $C$. devriesii. Generally speaking, maximum growth temperatures (MaxGT) of the dematiaceous fungi are not strict but range, e.g. from 38 to $42{ }^{\circ} \mathrm{C}$ in a principal dematiaceous fungal pathogen, Fonsecaea prodrosoi. The maximal growth temperature (MaxGT) of C. arxii for most isolates is probably in the range of $37-40^{\circ} \mathrm{C}$. The present fungus is clearly differentiated by conidial 
morphology, MaxGT and the identity (88\%) on the ITS region from C. bantiana, characterized by long ellipsoidal or nearly cylindrical conidia consisting of very long, poorly branched chains and a good growth at $37^{\circ} \mathrm{C}$ (MaxGT: $40-45^{\circ} \mathrm{C}$ ). It is time-consuming and needs expert knowledge to identify such a rare and slow-growing fungus, morphologically and physiologically. Analysis of the ITS region on rRNA gene is very helpful to make early diagnosis and species differentiation. However, we have to be careful when reading the names of fungi with sequence identities using the nucleotide databases of NCBI BLAST (National Center for Biotechnology Information, Basic Local Alignment Search Tool, U.S.). The fungal listings in these databases sometimes mention several or more names of fungi that actually belong to different genera or species. In order to obtain the correct name for a fungus, especially a filamentous one, morphological, some physiological and biochemical examinations should be done simultaneously.

Dematiaceous fungi have been recognized as etiologic agents of phaeohyphomycosis, chromoblastomycosis, and eumycotic mycetoma. Disseminated infection caused by dematiaceous fungi is uncommon, but it has been increasingly recognized as a cause of serious disease, especially in immunodeficient patients. Brain abscesses due to Cladophialophora bantiana are the commonest form of systemic phaeohyphomycosis [7]. Other localized deep forms of infections, such as arthritis [8], endocarditis [9], and osteomyelitis [10], have been rarely reported. Cladophialophora devriesii is a very rare pathogen and reported to have caused fatal dissemination [11] [12]. The present patient had femoral osteomyelitis due to Cladophialophora arxii. To the best of our knowledge, this is the first documented case of osteomyelitis caused by a dematiaceous fungus in CGD patients. In addition, C. arxii is an extremely rare species, and this is only the second reported case of $C$. arxii infection in 
humans.

Although guidelines for treatment of fungal osteomyelitis due to non-Aspergillus fungi are not well established, surgery generally plays an important role in the management of CGD patients [13]. In cases of Aspergillus osteomyelitis, surgical debridement appears to be very important for treatment, and extensive debridement is more effective than limited intralesional debridement [14]. Invasive fungal infections are a major cause of morbidity and mortality in CGD patients, and other rare and emerging fungi can cause significant diseases. Treatment of fungal infections involves prolonged use of systemic antifungal agents. In some cases, the causative fungi may be refractory to antifungal treatment. Therefore, whenever possible, extensive surgical debridement is also likely necessary for non-Aspergillus fungi osteomyelitis.

Itraconazole has a broad spectrum of activity against many infections caused by pathogenic fungi; it is well tolerated and safe [15], and prophylactic itraconazole is effective in preventing fungal infection in CGD patients [16]. However, low plasma itraconazole concentrations can cause failure of prophylaxis or treatment. Absorption of itraconazole when given as the capsule formulation is highly variable [17]. For example, adequate absorption requires an acid gastric environment and the presence of food.

In the present case, we selected itraconazole regardless of the patient suffering from fungal infection during itraconazole prophylaxis. The reason for this selection is the evidence that the CRP level, which had persisted over $10 \mathrm{mg} / \mathrm{l}$ for more than two weeks before admission, decreased from 13.8 to $6.6 \mathrm{mg} / \mathrm{l}$, and the $\beta$-D-glucan became negative $(<3.57$ $\mathrm{pg} / \mathrm{ml}$ ) by increasing itraconazole from $100 \mathrm{mg}$ to $200 \mathrm{mg}$ during four days until the diagnosis was made. In fact, the MIC of itraconazole was low and itraconazole had good in vitro activity against the fungus isolated. Although the MIC of itraconazole was very low $(0.03 \mathrm{mg} / \mathrm{l})$, the 
patient developed fungal osteomyelitis during itraconazole prophylaxis. In general, in vitro susceptibility testing for slow-growing organisms are problematic and not standardized [18]. The MICs of the present isolate were established after five days of incubation, but true MIC endpoints might have needed more incubation time because the isolated fungus grew extremely slowly. Furthermore, antifungal pharmacodynamic parameters in RPMI-1640, which is the standard synthetic medium for in vitro antifungal susceptibility testing, may not always predict antifungal activity in serum for azoles. Especially, highly protein-bound antifungal agents like itraconazole (protein binding, 99.8\%) have a trend toward higher MICs in the presence of serum [19]. In addition, the patient had taken prophylactic itraconazole capsules without food for several months before hospitalization. As a result, plasma concentrations of itraconazole may have decreased. Thus, we attribute the failure of prophylaxis to decreasing plasma concentrations of itraconazole. Therapy with escalating concentrations of itraconazole resulted in improvement of the laboratory results. Plasma itraconazole concentrations should be measured when there is failure of prophylaxis or treatment.

This is the first reported case of osteomyelitis due to dematiaceous fungi in CGD patients. The causative agent was found to be an extremely rare microorganism, $C$. arxii. The patient was successfully treated with surgical debridement, increasing concentrations of itraconazole, and IFN- $\gamma$ treatment. 
Shigemura et al.

\section{ACKNOWLEDGEMENTS}

The authors would like to thank Dr. Ayako Sano, Medical Mycology Research Center, Chiba University, Japan for her assistance to register the nucleotide sequence to DDBJ. 


\section{References}

1. Segal BH, Leto TL, Gallin JI, Malech HL, Holland SM: Genetic, biochemical, and clinical features of chronic granulomatous disease. Medicine (Baltimore). 2000; 79: 170-200.

2. Winkelstein JA, Marino MC, Johnston RB, Jr., Boyle J, Curnutte J, Gallin JI, Malech HL, Holland SM, Ochs H, Quie P, Buckley RH, Foster CB, Chanock SJ, Dickler H: Chronic granulomatous disease. Report on a national registry of 368 patients. Medicine (Baltimore). 2000; 79: 155-69.

3. Pfaller MA, Arikan S, Lozano-Chiu M, Chen Y, Coffman S, Messer SA, Rennie R, Sand C, Heffner T, Rex JH, Wang J, Yamane N: Clinical evaluation of the ASTY colorimetric microdilution panel for antifungal susceptibility testing. J Clin Microbiol. 1998; 36: 2609-12.

4. Cohen MS, Isturiz RE, Malech HL, Root RK, Wilfert CM, Gutman L, Buckley RH: Fungal infection in chronic granulomatous disease. The importance of the phagocyte in defense against fungi. Am J Med. 1981; 71: 59-66.

5. Sponseller PD, Malech HL, McCarthy EF, Jr., Horowitz SF, Jaffe G, Gallin JI: Skeletal involvement in children who have chronic granulomatous disease. J Bone Joint Surg Am. 1991; 73: 37-51.

6. Tintelnot K, von Hunnius P, de Hoog GS, Polak-Wyss A, Gueho E, Masclaux F: Systemic mycosis caused by a new Cladophialophora species. J Med Vet Mycol. 1995; 33: 349-54.

7. Revankar SG, Sutton DA, Rinaldi MG: Primary central nervous system phaeohyphomycosis: a review of 101 cases. Clin Infect Dis. 2004; 38: 206-16.

8. Ziza JM, Dupont B, Boissonnas A, Meyniard O, Bedrossian J, Drouhet E, Cremer GA: [Osteoarthritis caused by dematiaceous fungi. Apropos of 3 cases]. Ann Med Interne (Paris). 1985; 136: 393-7.

9. Gavin PJ, Sutton DA, Katz BZ: Fatal endocarditis in a neonate caused by the dematiaceous fungus Phialemonium obovatum: case report and review of the literature. $\mathrm{J}$ Clin Microbiol. 2002; 40: 2207-12.

10. Sharma NL, Mahajan V, Sharma RC, Sharma A: Subcutaneous pheohyphomycosis in India--a case report and review. Int J Dermatol. 2002; 41:16-20.

11. Gonzalez MS, Alfonso B, Seckinger D, Padhye AA, Ajello L: Subcutaneous phaeohyphomycosis caused by Cladosporium devriesii, sp. nov. Sabouraudia. 1984; 22: 427-32.

12. Mitchell DM, Fitz-Henley M, Horner-Bryce J: A case of disseminated 
phaeohyphomycosis caused by Cladosporium devriesii. West Indian Med J. 1990; 39: 118-23.

13. Seger RA: Modern management of chronic granulomatous disease. Br J Haematol. 2008; 140: 255-66.

14. Dotis J, Roilides E: Osteomyelitis due to Aspergillus spp. in patients with chronic granulomatous disease: comparison of Aspergillus nidulans and Aspergillus fumigatus. Int J Infect Dis. 2004; 8: 103-10.

15. Bodey GP: Azole antifungal agents. Clin Infect Dis. 1992; 14 Suppl 1: S161-9.

16. Gallin JI, Alling DW, Malech HL, Wesley R, Koziol D, Marciano B, Eisenstein EM, Turner ML, DeCarlo ES, Starling JM, Holland SM: Itraconazole to prevent fungal infections in chronic granulomatous disease. N Engl J Med. 2003; 348: 2416-22.

17. Poirier JM, Cheymol G: Optimisation of itraconazole therapy using target drug concentrations. Clin Pharmacokinet. 1998; 35: 461-73.

18. Rex JH, Pfaller MA, Walsh TJ, Chaturvedi V, Espinel-Ingroff A, Ghannoum MA, Gosey LL, Odds FC, Rinaldi MG, Sheehan DJ, Warnock DW: Antifungal susceptibility testing: practical aspects and current challenges. Clin Microbiol Rev. 2001; 14: 643-58

19. Zhanel GG, Saunders DG, Hoban DJ, Karlowsky JA: Influence of human serum on antifungal pharmacodynamics with Candida albicans. Antimicrob Agents Chemother. 2001; 45: 2018-22. 


\section{FIGURE LEGENDS}

Figure.1: Magnetic resonance imaging of the distal metaphysis of the left femur before treatment. The arrow indicates the site of the lesion. A: sagittal section. B: coronal section. Fig. 2. A: colony on SDA plate after 35 days incubation at $25^{\circ} \mathrm{C}$. B: Micrograph from a slide culture with PDA, branching conidial chains and liberated conidia. 
Figure 1.

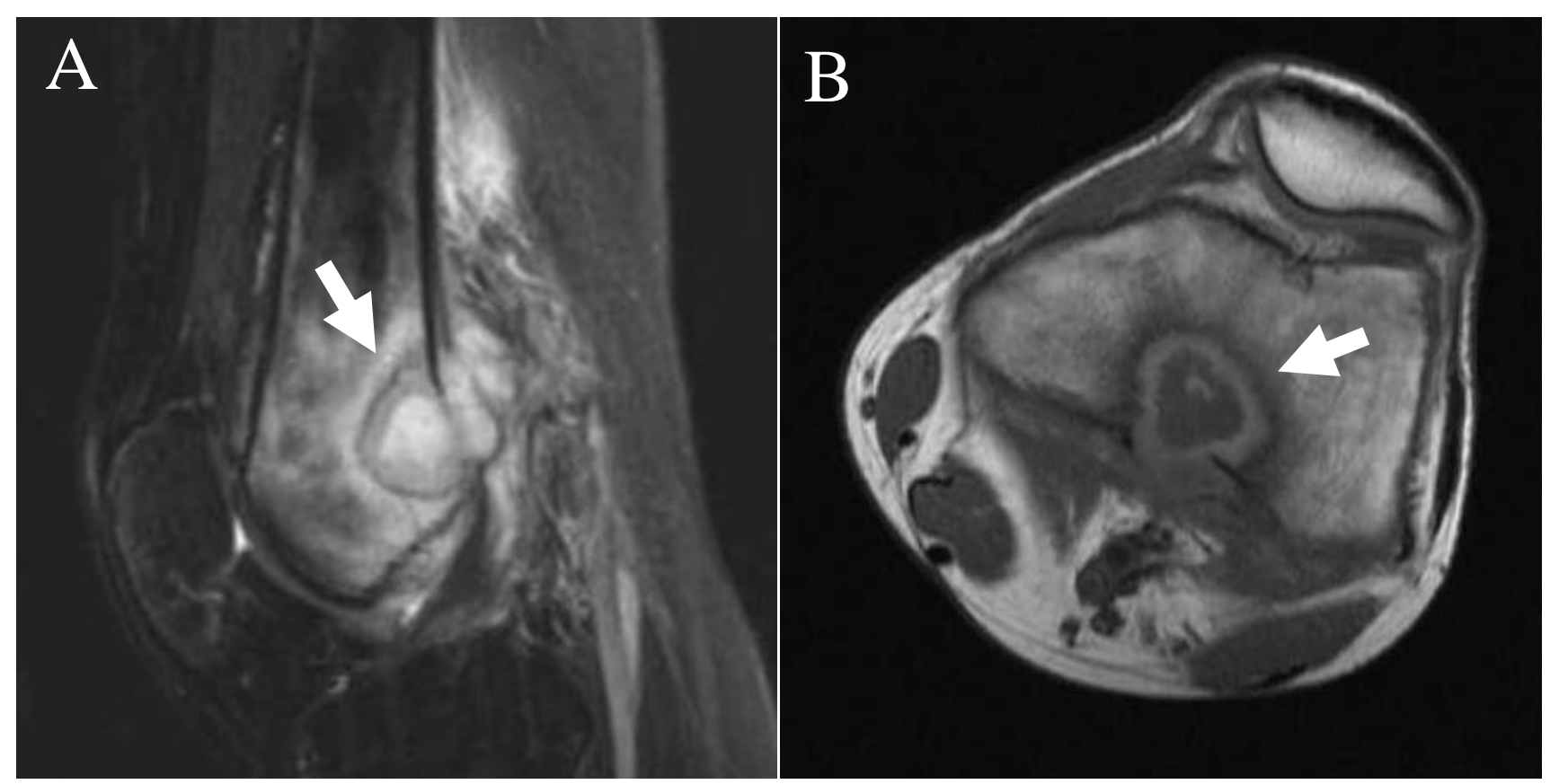


Figure 2.
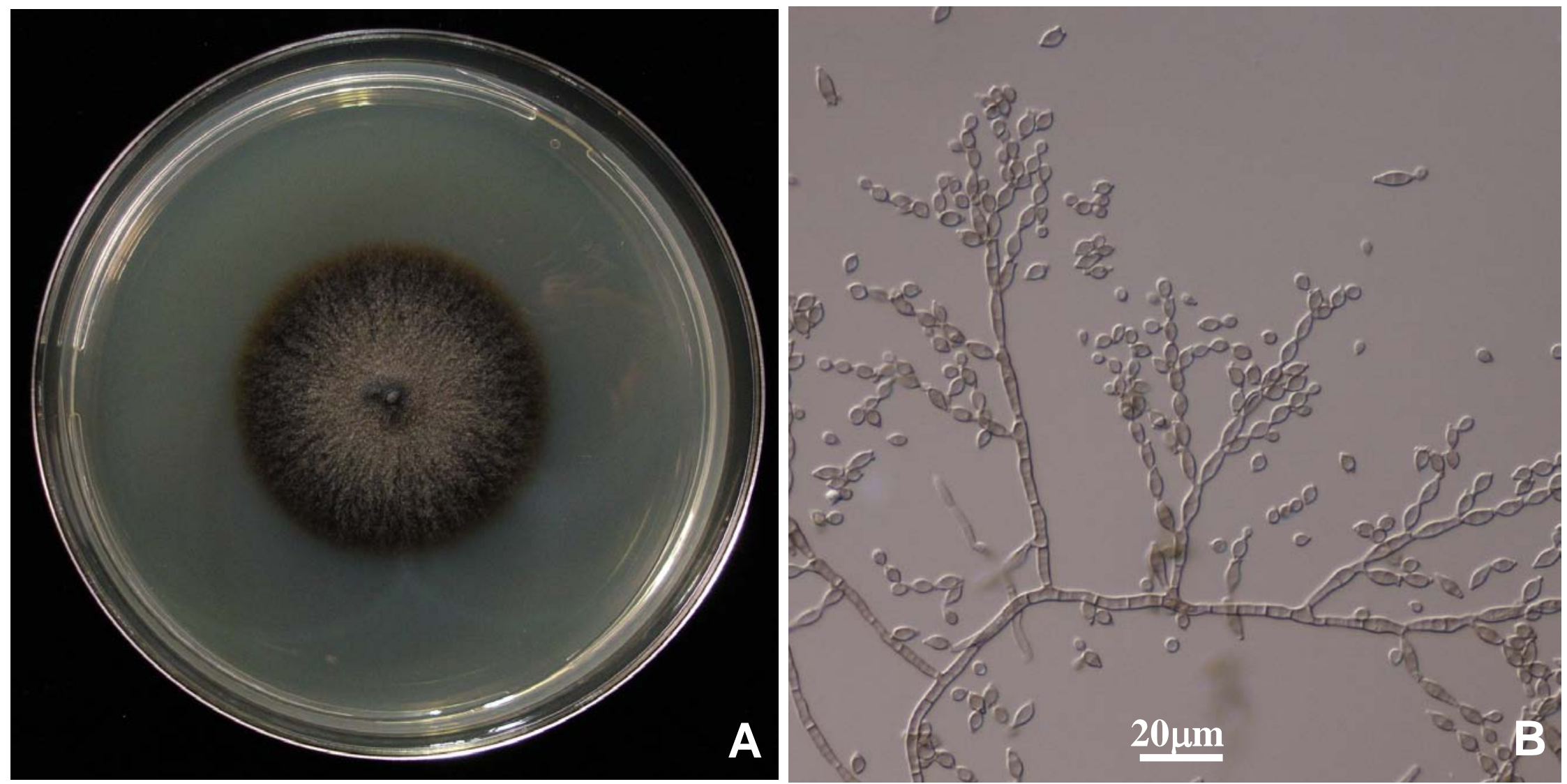